\title{
O PENSAMENTO DIRETIVO DAS COOPERATIVAS DA AGROINDÚSTRIA CANAVIEIRA DO PARANÁ À GUISA DA NOVA ECONOMIA INSTITUCIONAL ${ }^{1}$
}

\author{
Clédio Roberto Marschall ${ }^{2}$ \\ Darcy Jacob Rissardi Júnior ${ }^{3}$ \\ Denise Pastore de Lima ${ }^{4}$ \\ Pery Francisco Assis Shikida ${ }^{5}$
}

Resumo - Este estudo sobre o pensamento diretivo das cooperativas da agroindústria canavieira do Paraná objetiva resgatar os conceitos da Nova Economia Institucional e investigar o nível de tratamento da direção das cooperativas dado à questão dos custos de transação, formas de administração dos contratos, bem como às formas de governança que regem o segmento cooperativo agroindustrial canavieiro. O que se busca, neste trabalho, é explorar os aspectos comuns, pontos de tangência que podem trazer elementos úteis à aplicação da ciência das organizações e das instituições ao estudo das cooperativas da agroindústria canavieira.

Palavras-chave: Cooperativas, cana-de-açúcar, Nova Economia Institucional, Paraná.

\footnotetext{
${ }^{1}$ Recebido em 04/10/2004

Aceito em 05/11/2004

${ }^{2}$ Administrador, Coordenador de Programas de Qualidade da Cooperativa Agroindustrial Lar. Rua Goiás, 1904 CEP 85.884-000 - Medianeira-PR. Mestrando em Desenvolvimento Regional e Agronegócio da UNIOESTE - Toledo. Tel:45-264-5919. E-mail: cledio@lar.ind.br

${ }^{3}$ Administrador, Técnico Administrativo do Centro Federal de Educação Tecnológica do Paraná

- Unidade de Medianeira. Av. Brasil, 4232 CEP 85.884-000 - Medianeira-PR. Mestrando em Desenvolvimento Regional e Agronegócio da UNIOESTE - Toledo. Tel:45-264-6764.E-mail: darcy@md.cefetpr.br

${ }^{4}$ Tecnóloga em Alimentos. Técnico Administrativo do Centro Federal de Educação Tecnológica do Paraná

- Unidade de Medianeira. Av. Brasil, 4232 CEP 85.884-000 - Medianeira-PR. Mestranda em Desenvolvimento Regional e Agronegócio da UNIOESTE - Toledo. Tel:45-264-3679.E-mail: denise@md.cefetpr.br

${ }^{5}$ Economista, Mestre e Doutor em Economia Aplicada pela ESALQ/USP, Professor Adjunto do Curso de Ciências Econômicas e do Curso de Mestrado em Desenvolvimento Regional e Agronegócio da UNIOESTE Toledo. Rua da Faculdade, 645. CEP: 85.903-000. Toledo - PR. Tel:45-379-7000. Bolsista de Produtividade em Pesquisa do CNPq e Pesquisador Grupo de Pesquisa em Agronegócio e Desenvolvimento Regional (GEPEC). E-mail: pfashiki@unioeste.br
} 


\section{Introdução}

As transformações econômicas e sociais vividas nos últimos anos exigem formas eficientes de coordenação tanto em empresas quanto na sociedade como um todo. O cooperativismo emerge, neste início de século, como uma forma de governança alternativa, cujo objetivo é propiciar melhores condições de sobrevivência dos cooperados diante da dinâmica globalizante dos mercados. A sinergia obtida pela integração e coparticipação de seus membros é tida como importante diferencial competitivo comparado às demais formas organizacionais, especialmente quando se fala em economias de escala.

Essas e outras vantagens fizeram com que o número de estabelecimentos crescesse nos últimos anos, destacando o cooperativismo brasileiro no cenário mundial. Em 2003, havia no Brasil 7.355 cooperativas singulares e 81 cooperativas centrais, que geraram 182.000 empregos diretos e 5,762 milhões de associados, que participaram de um faturamento na ordem de $6 \%$ do PIB nacional (Organização das Cooperativas Brasileiras - OCB, 2003).

O cooperativismo paranaense representa $2,82 \%$ do total nacional, agrupando 208 cooperativas, sendo 68 no ramo agropecuário. Dentre estas, 9 são cooperativas agroindustriais processadoras de cana-de-açúcar, escopo deste trabalho. Essas agroindústrias estão situadas especialmente no norte e noroeste do estado, região que possui melhores condições edafoclimáticas para o cultivo da cana. As cooperativas são Cocamar Cooperativa Agroindustrial (Maringá), Cooperativa Agroindustrial Nova Produtiva (Astorga), Coocarol - Cooperativa Agroindustrial de Produtores de Cana de Rondon Ltda. (Rondon), Cocari - Cooperativa Agropecuária e Industrial (Marialva), Cofercatu - Cooperativa Agropecuária dos Cafeicultores de Porecatu Ltda. (Porecatu), Coopcana - Cooperativa Agrícola Regional de Produtores de Cana Ltda. (São Carlos do Ivaí), Cooperval Cooperativa Agroindustrial Vale do Ivaí Ltda. (Jandaia do Sul), Copagra Cooperativa Agrária dos Cafeicultores de Nova Londrina SRL (Nova Londrina) e Corol Cooperativa Agroindustrial (Rolândia). 
Clédio Roberto Marschall, Darcy Jacob Rissardi Júnior,

Essas cooperativas têm papel importante na produção açucareira paranaense. Segundo dados da Associação de Produtores de Álcool e Açúcar do Estado do Paraná (Alcopar), na safra 2002/2003, as cooperativas foram responsáveis por $26 \%$ da produção de cana moída no Paraná, o que resultou numa participação de $37 \%$ na produção de álcool anidro, $46 \%$ na produção de álcool hidratado e $8 \%$ na produção de açúcar.

No Brasil, a reestruturação pela qual o sistema vem passando teve seu marco especialmente após a Constituição Federal de 1988, em que houve uma série de itens desregulamentados, como, por exemplo, a desvinculação das cooperativas do Instituto de Colonização e Reforma Agrária - INCRA. Essas mudanças introduziram as cooperativas em uma administração empresarial, cujo papel fundamental é caracterizado pela viabilização de seus sócios, que, em certo momento, são os donos e, em outros, são clientes do empreendimento cooperativado.

Em termos estaduais, segundo ALCOPAR (2003 e 2004a), a agroindústria canavieira do Paraná conta, atualmente, com 27 unidades produtoras de açúcar e álcool - de modo geral, de perfil moderno - atingindo economicamente 126 municípios, com geração de cerca de 74 mil empregos diretos e movimentação financeira de cerca de $\mathrm{R} \$ 2$ bilhões. A produção de cana no estado tem acompanhado as vicissitudes da indústria sucroalcooleira, mediante investimentos na ampliação da área de cultivo e no volume de cana produzida, além de elevação na produtividade e da melhoria da qualidade da matéria-prima. Ademais, entre os principais subprodutos derivados da economia canavieira, o bagaço da cana é destinado à geração de energia calorífera em unidades termoelétricas, além de constituir suplemento para a engorda de animais.

No âmbito do agregado total, as usinas e destilarias ocupam 2\% da área agricultável do estado - sobretudo nas regiões norte e noroeste (ALCOPAR, 2002). Hoje, existem mais de 300 mil hectares plantados no estado e um enorme potencial que pode ser ocupado pela cultura. Em termos quantitativos, o Paraná vem se destacando pela sua produtividade média (74 t/ha, nas doze últimas safras - para efeito de cotejo, a 
média nacional está abaixo deste patamar), pelo $2^{\circ}$ lugar nas produções de cana-de-açúcar e álcool e pelo $3^{\circ}$ lugar na produção nacional de açúcar (sendo responsável por $7,5 \%$ da produção canavieira, $7,9 \%$ da produção alcooleira e 6,6\% da produção açucareira do país, safra 2002/03) (ALCOPAR, 2003).

O mapa, a seguir, apresenta as usinas e destilarias do estado do Paraná e suas localizações.

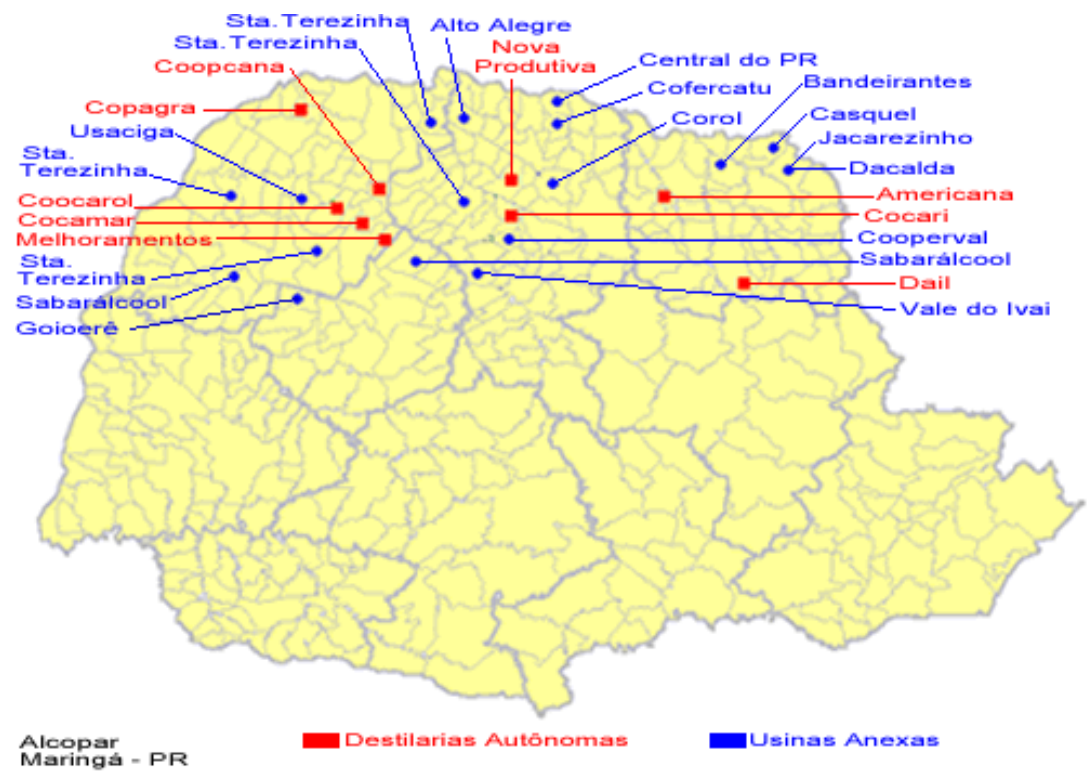

Fonte: ALCOPAR (2004).

O estudo sobre o pensamento diretivo das cooperativas da agroindústria canavieira no Paraná pretende resgatar os conceitos de autores da Nova Economia Institucional e analisar o nível de tratamento da direção das cooperativas dado à questão dos custos de transação, formas de administração dos contratos, bem como às formas de governança que regem o segmento cooperativo agroindustrial canavieiro. O que se busca, neste trabalho, é explorar os aspectos comuns, pontos de tangência que podem trazer elementos úteis à aplicação da ciência das organizações e das 476 
Clédio Roberto Marschall, Darcy Jacob Rissardi Júnior,

Denise Pastore de Lima \& Pery Francisco Assis Shikida

instituições ao estudo das cooperativas da agroindústria canavieira.

Além desta introdução, este artigo expõe, na ordem, o referencial teórico e metodologia, os resultados e discussões e as considerações finais.

\section{Referencial teórico e metodologia}

A Nova Economia Institucional (NEI), disseminada pela obra de Coase (1937) e Williamson (1985), consolidou a linha de estudos sobre a eficiência das organizações por meio da análise das transações, sobretudo com uma visão microanalítica. Essas transações podem apresentar-se de diversas formas, desde a simples aquisição de matéria-prima no mercado spot, ou seja, transações que se resolvem em um único instante de tempo (Azevedo, 2001), até a integração vertical (aquisição de sócios ou terceiros) e horizontal (produção própria).

Destarte, o ambiente institucional é tratado, por Saes (2000), como uma estrutura de regras que permite a interação humana, seja no campo político, seja no social ou econômico. Essas regras podem ser formais ou informais. São formais quando explicitadas por algum poder legítimo e tornadas obrigatórias para manter a ordem e o desenvolvimento de uma sociedade, a exemplo da Constituição Federal, das leis, dos estatutos e dos regimentos das organizações.

O próprio sistema de organização cooperativista pode ser visto como parte dessa nova visão da economia da firma, já que faz parte do que Coase (1937) chamou de coordenação. A cooperativa pode ser vista como forma de coordenação das relações contratuais, ou seja, uma forma de organização entre seus membros para produção de bens finais. A questão toma outra forma quando a própria cooperativa assume o papel de industrializar a produção dentro da estrutura do $\mathrm{SAG}^{6}$, estando na posição de empresa e, ao mesmo tempo, de entidade organizacional,

\footnotetext{
${ }^{6}$ Um Sistema Agroindustrial (SAG) é visto como um conjunto de relações contratuais entre empresas e agentes especializados, cujo objetivo final é disputar o consumidor de determinado produto (Zylbersztajn, 2000).
} 
com a missão de maximizar os rendimentos de seus associados via produção integrada e, ao mesmo tempo, permanecer no mercado (cada vez mais globalizado e competitivo). No papel de empresa, a cooperativa também encontra formas de se organizar, unindo-se em Cooperativas Centrais para produção de algum ativo específico e, ou, racionalizando custos no gerenciamento de algum processo produtivo ou gerencial.

Segundo Neves et al. (1998), para determinação das estruturas de governança mais eficientes, opta-se por aquela que proporciona menores custos transacionáveis, que, por sua vez, são determinados pelos atributos das transações.

Ressalta-se que as formas eficientes de governança contratual devem considerar os riscos mencionados e optar pelo maior ou menor controle das transações. O produtor de cana-de-açúcar assume todos os riscos de condições climáticas, doenças/pragas, entre outros ligados à produção, como também assume os riscos de a Cooperativa não monitorar a qualidade de sacarose, quando são feitas amostras nas Cooperativas (Neves et al., 1998).

Williamson (1985) definiu os custos de transação como os "custos de funcionamento do sistema econômico". Entende-se este conceito como os custos relacionados indiretamente com a produção, que surgem a partir do relacionamento entre os agentes, em virtude de problemas de coordenação. Este autor subdividiu o conceito de custos de transação em dois grupos: os gerados antes da transação, ex-ante, como a elaboração e negociação dos contratos e a procura e o conhecimento da outra parte contratante; e os custos ex-post, originados após a concretização do negócio, tais como o monitoramento das imposições contratuais, da resolução de conflitos que possam ocorrer e das readaptações que poderão ser necessárias.

Wiliamson (1985) definiu, também, alguns atributos de uma transação, tais como freqüência e especificidade dos ativos. 
Clédio Roberto Marschall, Darcy Jacob Rissardi Júnior,

Denise Pastore de Lima \& Pery Francisco Assis Shikida

A freqüência é uma medida da recorrência com que uma transação se efetiva. Quanto maior a freqüência, menores serão os custos fixos médios associados à coleta de informação e à elaboração de um contrato complexo que imponha restrições ao comportamento oportunista.

A especificidade dos ativos envolvidos tem papel de variável-chave nessa análise. Ativos serão específicos, se o retorno associado a eles depender da continuidade de uma transação específica. Quanto maior a especificidade dos ativos, maior será a perda associada a uma ação oportunística por parte de outro agente, como conseqüência, maior serão os custos de transação.

Há transações caracterizadas por ativos de baixa especificidade que indicam, no caso de ruptura dos contratos, que os agentes não sofrerão perdas, podendo reatar as relações contratuais com outros agentes no mercado. Essas transações são mais eficientemente regidas pelo sistema de preços e caracterizam-se por produtos homogêneos, em que muitos produtores e compradores não precisam de identificação.

Para o produtor de cana-de-açúcar, o ativo inicial são a terra, a mão-deobra e os equipamentos. São ativos de baixa especificidade, podendo ser utilizados em outras culturas, caso se trate de áreas de expansão. Como o investimento no plantio de cana-de-açúcar é feito por um período mínimo de 5 anos, depois de tomada a decisão pelo plantio, o produtor passa a contar com um produto com elevadas especificidades locacionais e temporais, portanto, seu grau de dependência de uma unidade esmagadora passa a ser grande, uma vez que só existe consumo do produto processado, e não há o de cana crua. Caso na região existam diversas unidades que disputam a matéria-prima, estas ficam em situação privilegiada, pois podem trabalhar com mais de uma oferta. Porém, se numa distância economicamente viável existir apenas uma cooperativa ou usina, o produtor tornar-se-á dependente desta, não havendo a ação de oportunismo. Para as cooperativas ou usinas, a análise é semelhante, a dependência da usina pela entrega da matéria-prima por parte do cooperado é influenciada por vários fatores, como a percentagem de cana 
própria e a capacidade de esmagamento. A usina com baixa percentagem de cana própria e elevada capacidade de esmagamento terá dependência maior do fornecedor, principalmente se a propriedade for localizada próxima (Shikida, 1997; Neves et al., 1998).

Com o emprego dos ativos específicos à transação, tem-se uma quaserenda, que se caracteriza pela diferença entre o retorno advindo do emprego destes na transação específica, comparado com outro emprego alternativo. A quase-renda depende da continuidade da relação, e cada uma das partes terá incentivos para apropriar-se de qualquer ganho incremental derivado dessa relação conjunta, gerando a possibilidade de comportamento oportunístico, ou hold up (quebra contratual). Como resultado, ter-se-á o estabelecimento de uma relação de dependência entre as partes, à medida que se elevar a especificidade dos ativos.

Para abordar o estudo descrito, optou-se por realizar uma pesquisa junto às cooperativas produtoras de cana-de-açúcar do estado do Paraná. O instrumento de coleta de dados foi constituído por uma série ordenada de perguntas, que foram respondidas por escrito, sem a presença do entrevistador (Marconi e Lakatos, 1996). A metodologia empregada foi a de uma pesquisa de observação direta extensiva, realizada por meio de técnica de interrogação mediante aplicação de questionário.

Dado o universo a ser pesquisado (nove cooperativas), optou-se por realizar um censo, enviando-se o formulário a todas as cooperativas da agroindústria canavieira do Paraná. Por decisão interna de não divulgação de dados, duas cooperativas não devolveram o questionário preenchido. Portanto, a amostra do presente trabalho representa $77,8 \%$ do total da população, o que evidencia boa representatividade.

Por critérios definidos previamente e com vistas em manter o anonimato das cooperativas e de seus respondentes (neste caso, a diretoria), os resultados serão tabulados e analisados de forma agregada. 
Clédio Roberto Marschall, Darcy Jacob Rissardi Júnior,

Denise Pastore de Lima \& Pery Francisco Assis Shikida

\section{Resultados e discussão}

Como principais resultados na transação que ocorre entre os agentes responsáveis pela produção agrícola e a agroindústria processadora, a produção agrícola é originária, em sua maioria, de produtores associados, ou seja, $83 \%$ das cooperativas pesquisadas adquirem a produção ou parte dela do quadro social.

Um aspecto interessante da agroindústria canavieira cooperativada do Paraná recai sobre a predominância temporal em que surgiram. Shikida (1997) alertou para o período de "expansão do Proálcool" nos anos de 1975 a 1985, em que se intensificaram os investimentos na agroindústria canavieira, motivados pelos incentivos governamentais via regulamentação do mercado (redução do Imposto sobre Produtos Industrializados e Imposto sobre Propriedade de Veículos Automotores), e por uma situação favorável de mercado, em que os preços internacionais favoreciam a fabricação do álcool como combustível alternativo. Na pesquisa, sete das nove cooperativas iniciaram suas atividades agroindustriais canavieiras no período citado, aproveitando-se dessas externalidades positivas. Pôdese evidenciar, inclusive, que algumas delas utilizaram a "diversificação concêntrica", estratégia de crescimento apontada por Azevedo (2000) como forma de satisfazer a suas estratégias de crescimento, dadas as facilidades e, evidentemente, as condições edafoclimáticas de cada região. Esse tipo de diversificação foi experimentado por $57 \%$ das cooperativas pesquisadas. Essas cooperativas atuam em outras atividades e encontraram na agroindústria canavieira uma forma de diversificar suas atividades. Foi também nesse período que surgiram as principais entidades organizadas da agroindústria canavieira paranaense, como Associação de Produtores de Álcool e Açúcar do Estado do Paraná (ALCOPAR), em 1981, Sindicato da Indústria de Fabricação de Álcool do Estado do Paraná (SIALPAR), em 1986, e Sindicato da Indústria de Açúcar do Estado do Paraná (SIAPAR), em 1988. 
No estado do Paraná, as cooperativas apresentam bom nível de organização, estando todas associadas pelo menos a uma entidade. Por questão legal, todas são associadas à Organização das Cooperativas do Estado do Paraná, OCEPAR, são cooperativas singulares e não participam, com cotas, em cooperativas centrais. Todas as cooperativas investigadas produzem álcool hidratado e anidro, sendo representadas pela ALCOPAR, SIALPAR e SIAPAR (Figura 1). Segundo North (1990), as instituições estão para as "regras do jogo", assim como as organizações estão para os jogadores", destacando, assim, a importância das organizações de representação cooperativista.

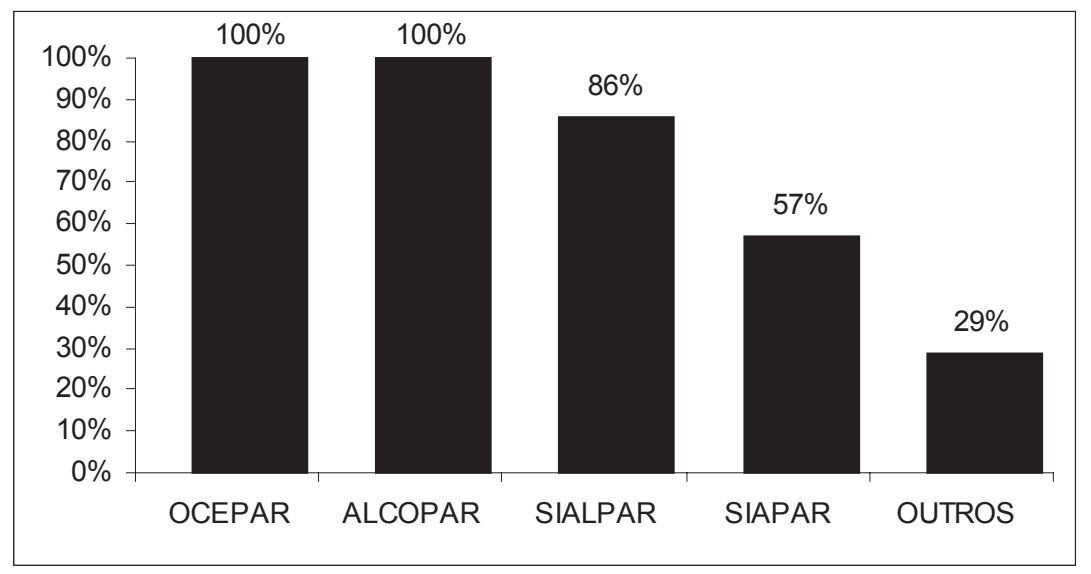

Fonte: Dados da pesquisa.

Figura 1 - Gráfico de participação em entidades organizacionais. 
Clédio Roberto Marschall, Darcy Jacob Rissardi Júnior,

Na pesquisa realizada percebe-se, fortemente, a influência negativa das instituições formais no desempenho e, ou, no desenvolvimento das cooperativas, especialmente a legislação tributária, apontada por $71 \%$ das cooperativas, seguida pela legislação trabalhista, apontada por $57 \%$ das cooperativas pesquisas (Figura 2).

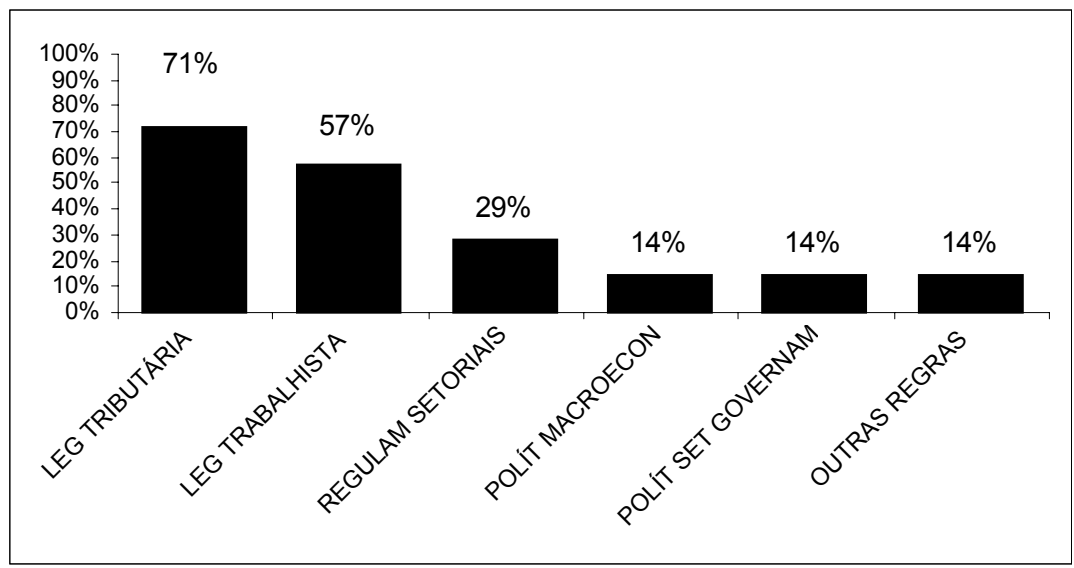

Fonte: Dados da pesquisa.

Figura 2 - Instituições formais que influenciam, negativamente, o desempenho.

As regulamentações setoriais apresentam menor influência no ambiente organizacional cooperativista em estudo, em razão do alto nível de organização do setor. Políticas macroeconômicas e setoriais governamentais para o setor também têm pouca influência, com o mesmo percentual de participação.

Por influir positivamente no desempenho das cooperativas canavieiras paranaenses, percebe-se que a legislação tributária cresce em importância, já que apresentou índices idênticos aos de políticas macroeconômicas e políticas setoriais governamentais, com $29 \%$, o que indica um paradoxo, ao se analisarem os efeitos positivos diante dos negativos. No entanto, os impostos influem, positivamente, no desempenho, na medida em que o setor goza de redução do PIS/COFINS, um imposto pago sobre o 
faturamento das operações do chamado ato cooperativo, ou seja, sobre as operações realizadas com associados nas atividades fins da cooperativa (Figura 3).

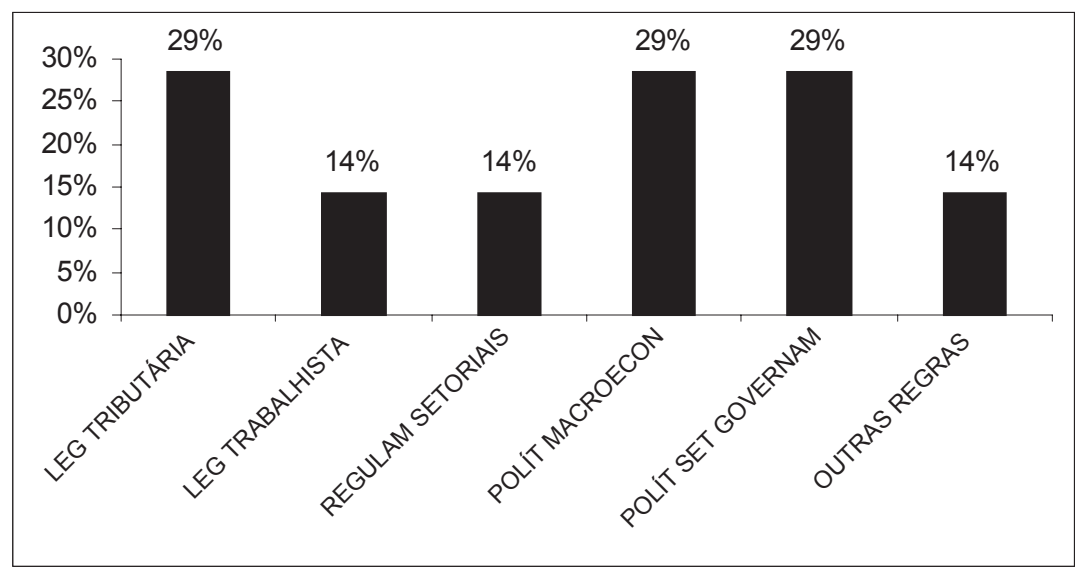

Fonte: Dados da pesquisa.

Figura 3 - Instituições formais que influenciam, positivamente, o desempenho.

Sobre as regras informais, concluiu-se que elas não influem substancialmente, de forma negativa, no desempenho das cooperativas, pois apenas $14 \%$ responderam que outras regras informais afetam seu desempenho. No entanto, essas regras influem decisivamente, de forma positiva, no desempenho das cooperativas (Figura 4). 


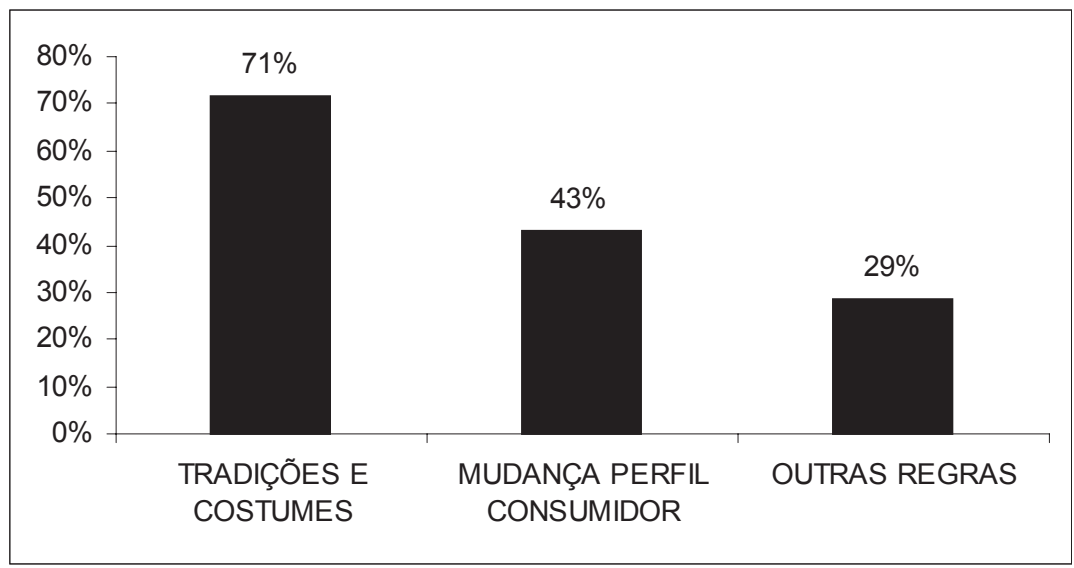

Fonte: Dados da pesquisa.

Figura 4 - Instituições informais que influenciam, positivamente, o desempenho.

Conforme Figura 4, para 71\% das cooperativas, as tradições e os costumes influem, positivamente, no bom desempenho do agronegócio canade-açúcar. Segundo o ex-professor da Unicamp, Isaías de Carvalho Macedo, que até recentemente ocupava o cargo de gerente de tecnologia da Cooperativa de Produtores de Cana-de-açúcar, Açúcar e Álcool do Estado de São Paulo (COPERSUCAR), ainda há resistência, por parte do consumidor, em migrar para os produtos substitutos aos derivados do açúcar, pois o "mercado consumidor de açúcar cresce 1,5\% ao ano, independente da competição exercida pelos produtos dietéticos" (UNICAMP, 2001). No álcool, espera-se que com a inovadora tecnologia flexpower, oferecida ao consumidor sem custo adicional, ocorra um incremento considerável no consumo, já que os veículos equipados com a tecnologia podem ser abastecidos com álcool, gasolina ou a mistura de ambos, em qualquer proporção.

Buscou-se, ainda nesta pesquisa, verificar as formas de transação para obtenção da matéria-prima agroindustrial canavieira. 
Nesta pesquisa, $86 \%$ das cooperativas praticavam a integração vertical, ou seja, adquiriam a produção de produtores rurais. A esse tipo de transação no agronegócio da cana, o nome mais pertinente é o de "produção integrada". Contudo, um número também significativo busca uma ocupação maior de sua capacidade, produzindo simultaneamente em áreas próprias via integração horizontal. A aquisição de matéria-prima de pessoas jurídicas (firmas) é feita por $29 \%$ das empresas pesquisadas.

No que se refere aos custos ex-post, que podem ser representados pelos gastos com custas judiciais referentes a contratos mal coordenados/ sucedidos (causas perdidas, atrasos, erros ou omissões), na área da agroindústria canavieira cooperativada, $71 \%$ afirmaram que não havia esses custos de transação e $29 \%$ afirmaram que os custos eram baixos.

Como é de esperar, quanto aos custos ex-ante, 71\% das cooperativas possuíam uma área ou processo organizacional responsável pelo desenho, estruturação, monitoramento e garantia da implementação dos contratos da Cooperativa. No entanto, 29\% afirmaram que não possuíam gerenciamento de contratos entre produtor e cooperativa. Ademais, foi apontado também que $71 \%$ das Cooperativas da Agroindústria Canavieira do Paraná não faziam previsão de custos para o gerenciamento de contratos ou causas judiciais.

No segmento cooperativista canavieiro paranaense, a freqüência foi ainda considerada como diferencial importante para redução de custos expost, pois $43 \%$ das cooperativas afirmaram que as transações com cooperados asseguravam menor risco nos contratos. Contudo, evidencia-se ainda, com intensidade, o comportamento oportunista do cooperado para com a cooperativa, uma vez que, na opinião de $57 \%$ dos dirigentes de cooperativas, as transações com cooperados não asseguravam menor risco nos contratos. Não obstante, percebe-se ainda a prevalência da maioria sobre os valores e ideologias, visto que $71 \%$ dos dirigentes da agroindústria canavieira do Paraná afirmaram haver bom nível de fidelidade, pois não experimentaram quebras contratuais. Para $29 \%$ das cooperativas que já experimentaram esse tipo de custo de transação, o mo- 
Clédio Roberto Marschall, Darcy Jacob Rissardi Júnior,

tivo é a concorrência com outros produtos, como a soja, por exemplo. As cooperativas agrícolas consideram que os seus princípios doutrinários são a base da eficiência cooperativa (Bialoskorski Neto, 2000).

Conforme apuração no trabalho, a quebra contratual é de difícil monitoramento ou antecipação. Algumas cooperativas buscam punir os seus membros que assim agem, sendo $43 \%$ das punições de ações judiciais.

As motivações que levam à quebra contratual por parte da cooperativa assim se configuram: $29 \%$ devido à capacidade de produção limitada por parte da cooperativa; $7 \%$, pelo não cumprimento das obrigações por parte do cooperado; $7 \%$, por diferencial de preços. Na pesquisa, $57 \%$ afirmaram que não houve quebra contratual por parte delas e $100 \%$ das cooperativas responderam que esta não ocorreu devido à qualidade da matéria-prima (Figura 5).

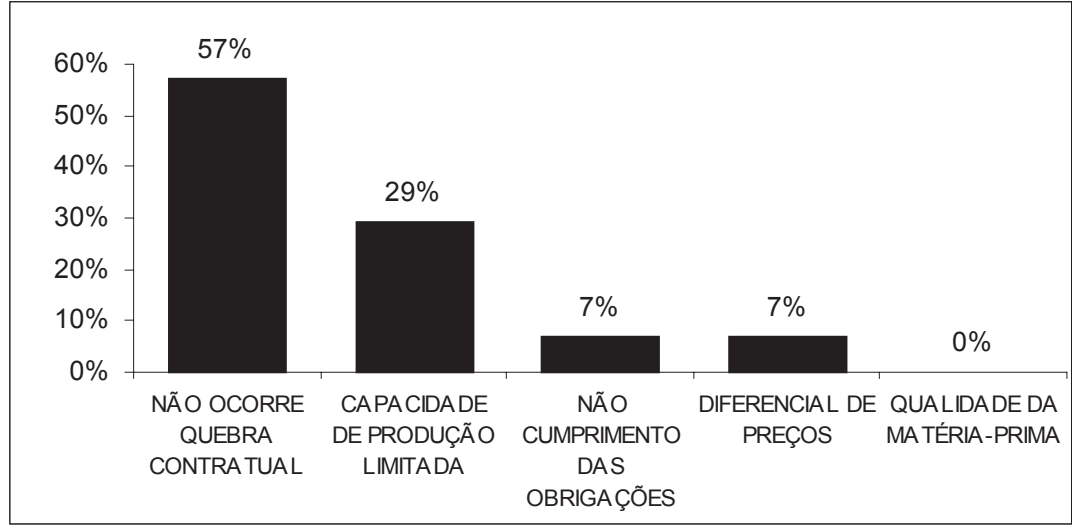

Fonte: Dados da pesquisa.

Figura 5 - Gráfico de motivações que levam à quebra contratual por parte da cooperativa. 
No levantamento, observou-se ainda que $60 \%$ das cooperativas não são punidas pela quebra de contrato com o associado e, quando esta ocorre, é definida judicialmente. Dessa forma, os contratos sempre serão incompletos, gerando a possibilidade de ações oportunísticas de ambas as partes, devido às imperfeições nos termos contratuais (Rocha Júnior, 2001).

No que tange às salvaguardas, observa-se que as cooperativas concorrem, em desvantagens, com a empresa privada, já que, para $86 \%$ das cooperativas pesquisadas, o fato de serem cooperados não lhes garante menores exigências de salvaguardas contratuais, o que leva a crer que problemas decorrentes do oportunismo dos agentes e da falta de incentivos possam também estar presentes em relações contratuais com os cooperados (Figura 6).

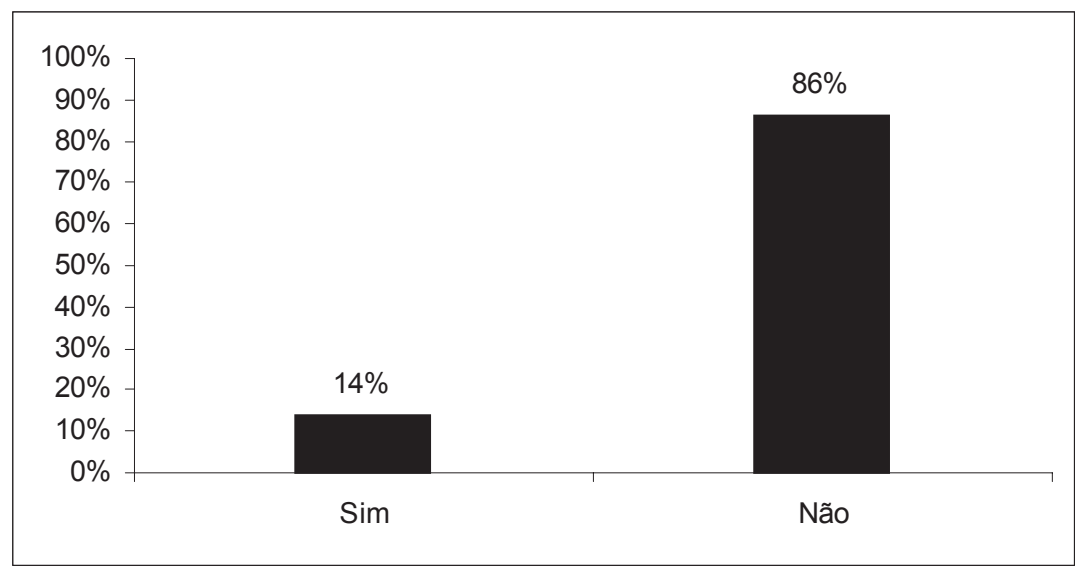

Fonte: Dados da pesquisa.

Figura 6 - Diferencial de salvaguardas contratuais entre cooperados e não-cooperados. 
Clédio Roberto Marschall, Darcy Jacob Rissardi Júnior,

Em relação aos recursos destinados para modernizar e realizar pesquisas, entre outros, observa-se que as organizações cooperativas encontram os mesmos problemas para acesso ao capital, os quais afetam outros setores da economia, uma vez que $86 \%$ delas utilizam recursos próprios para projetos de modernização e pesquisa na organização (Figura 7).

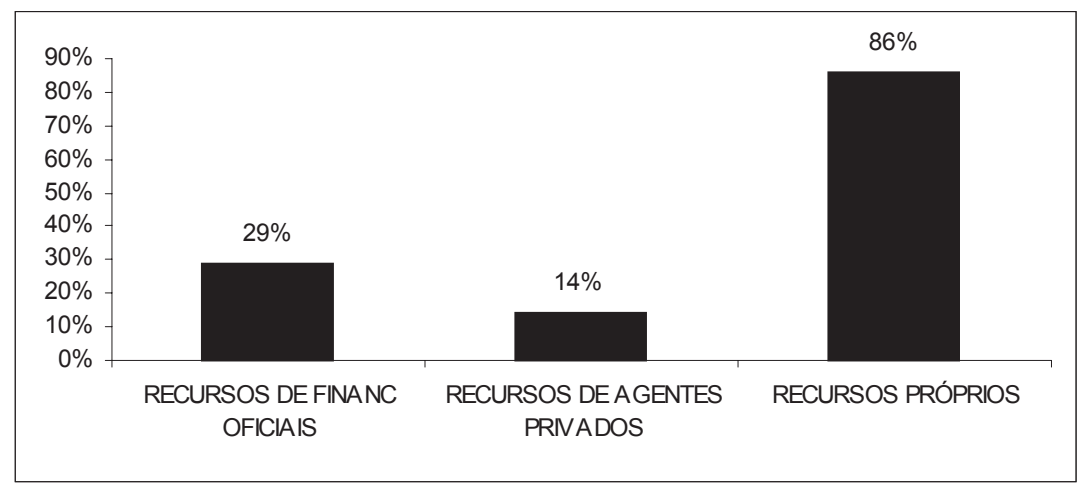

Fonte: Dados da pesquisa.

Figura 7 - Origem dos recursos destinados à modernização, pesquisa, etc.

O aporte de recursos próprios tem limitações típicas de escala. Apenas com os recursos dos membros, as cooperativas ficam limitadas a projetos de menor escala e escopo, tendo ainda de criar mecanismos de retenção de sobras, pois dificilmente as cooperativas conseguem incentivar os membros a capitalizar diretamente a cooperativa.

Até a década de 80, a agroindústria canavieira cresceu sob o amparo do Estado. Isto fez com que várias empresas pouco se preocupassem com a produtividade, vivendo dentro de um "paradigma subvencionista" (isto é, dependendo de subsídios do governo para se manter lucrativa). Contudo, estão surgindo empresas preocupadas com a melhoria tecnológica, tanto na área agrícola quanto na industrial, que estão se orientando por meio de um "paradigma tecnológico" (ou seja, são lucrativas sem subsídios do governo). Estas últimas estão tendo melhor desempenho (Shikida, 1998). 
No caso das cooperativas paranaenses, houve quase unanimidade na retirada do Estado do setor, conforme dados levantados na pesquisa, ou seja, $86 \%$ das cooperativas que atuam no setor de cana-de-açúcar afirmaram que as perspectivas do setor melhoraram com o fim do intervencionismo estatal, enquanto apenas uma cooperativa $(14 \%$ da amostra) afirmou que as perspectivas na produção de açúcar e álcool pioraram com a desregulamentação do setor (Figura 8).

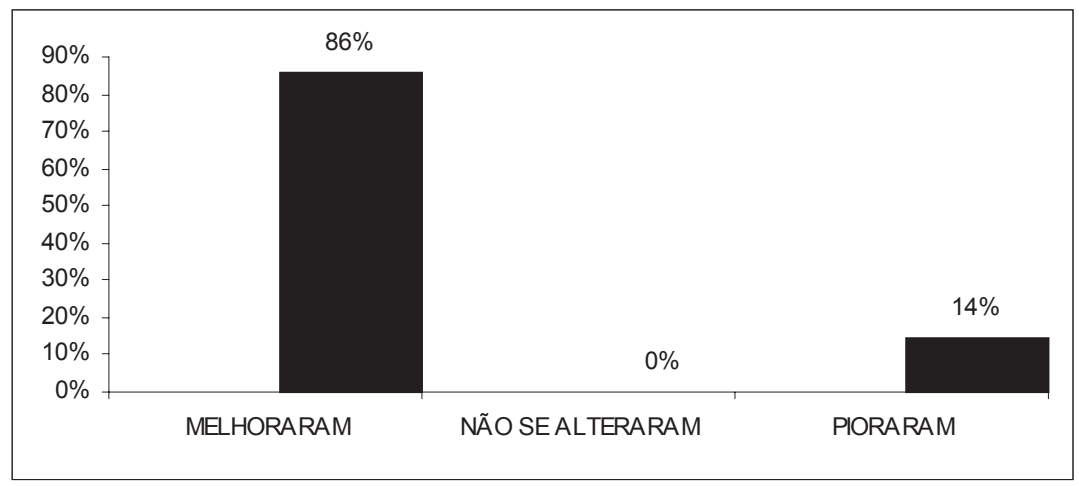

Fonte: Dados da pesquisa.

Figura 8 - Perspectivas de produção com a desregulamentação do setor.

Processos de desregulamentação setorial e de abertura comercial representam mudanças institucionais que aumentam a pressão competitiva e ampliam e alteram as estratégias de concorrência e crescimento, com impactos diretos na organização dos sistemas produtivos e no seu conjunto de regras formais e informais vigentes, e passam a ser decisivos na delimitação das assimetrias e na avaliação de uma nova eficiência para as firmas (North, 1990).

\section{Conclusões}

Este artigo objetivou apresentar um estudo sobre o pensamento da alta direção das cooperativas da agroindústria canavieira paranaense, sob o enfoque da Nova Economia Institucional, importante corpo teórico que 
Clédio Roberto Marschall, Darcy Jacob Rissardi Júnior,

Denise Pastore de Lima \& Pery Francisco Assis Shikida

surgiu nos últimos anos e que tem sido um considerável apoio à análise econômica da firma.

Por meio da pesquisa efetuada, observou-se que as cooperativas agrícolas, corroborando com a opinião de diversos autores, podem ser vistas como arranjos contratuais com características próprias que as distinguem de outros arranjos e que, vistas como uma rede de contratos, têm a vantagem de coordenar complexos sistemas produtivos.

No caso das cooperativas da agroindústria canavieira paranaense, notase que a coordenação deste complexo sistema produtivo tem apresentado resultados positivos para a economia paranaense e que a eficiência das transações, de maneira geral, com baixas assimetrias de informação, custos (ex-ante e ex-post) controlados e poucas ações oportunísticas entre os agentes, proporciona, entre outras coisas, um ambiente institucional e organizacional definido.

Em um cenário de mudanças pelas quais passam a agroindústria canavieira e os sistemas cooperativos mundiais, o pensamento diretivo destas organizações torna-se importante fonte de informações para definição da direção do curso adotado e para inserção em uma economia de mercado cada vez mais competitiva, cujos princípios doutrinários são seguidos por seus dirigentes e cooperados.

Finalmente, cabe ressaltar que este trabalho seguiu determinado rumo teórico-metodológico, num universo de inúmeras diretrizes que poderiam ser utilizadas na análise desse objeto de estudo. Não obstante, se proporcionar ganhos para o debate acerca das agroindústrias canavieiras cooperativadas, este trabalho terá cumprido um dos papéis prescípuos da pesquisa, que é estimular/enriquecer a discussão científica, seja no âmbito da academia, seja fora dela. 


\section{Referências bibliográficas}

ALCOPAR (2004). Disponível em: <http://www.alcopar.org.br>. Acesso em: 18/08/2004.

ALCOPAR (2004a). Histórico produção Paraná. Disponível em: <http:/ /www.alcopar.org.br/histprod_br/index.htm>. Acesso em: 19/01/2004.

ALCOPAR. Cana deve movimentar R $\$ 2$ bi em 2003. Paraná açúcar e álcool. Informativo mensal da Associação de Produtores de Álcool e Açúcar do Estado do Paraná - ALCOPAR. Maringá, Ago. 2003. Disponível em: $<$ http://www.jornalparana.com.br/anteriores/index.htm $>$. Acesso em: 15/12/2003.

ALCOPAR. O setor de açúcar e álcool no Paraná. Paraná açúcar e álcool. Informativo mensal da Associação de Produtores de Álcool e Açúcar do Estado do Paraná - ALCOPAR. Maringá, Ano V, n. 70, Abr. 2002. p.10.

AZEVEDO, P. F. Comercialização de produtos agroindustriais, cap 2. In BATALHA, M.O. (Org.), 2001. Gestão agroindustrial, Vol. I, São Paulo: Atlas, 2001. p. 64-98.

AZEVEDO, P. F. Concorrência no Agribusiness, cap 4. In: ZYLBERSZTAJ, D.; NEVES. M. F. (Orgs). Economia \& gestão dos negócios agroalimentares. São Paulo, Pioneira/PENSA, 2000. p. 6079 .

BIALOSKORSKI Neto, S. A nova geração de cooperativas e a coordenação de sistemas Agroindustriais. Trabalho discutido durante o II Workshop Brasileiro de Gestão de Sistemas Agroalimentares - Ribeirão Preto FEA-USP Novembro de 1999. 
Clédio Roberto Marschall, Darcy Jacob Rissardi Júnior,

Denise Pastore de Lima \& Pery Francisco Assis Shikida

BIALOSKORSKI Neto, S. Agribusiness cooperativo. In: ZYLBERSZTAJ, D.; NEVES. M. F. (Orgs). Economia \& gestão dos negócios agroalimentares. São Paulo, Pioneira/PENSA, 2000. p. 235253.

COASE, R.H. 1937. "The nature of the firm". Economic, 4:386-405, reprinted in Coase, 1998, "The firm, the Market and the Law". Chicago: University of Chicago Press, Chapter 2.

MARCONI, M. A.; LAKATOS, E. M. Técnicas de pesquisa. São Paulo: Atlas, 1996.

NEVES, M.F; WAACK, R.S. \& MARINO, M.K. Sistema agroindustrial da cana-de-açúcar: caracterização das transações entre empresas de insumos, produtores de cana e usinas. Anais do XXXVI Congresso de Economia e Sociologia Rural - SOBER, Poços de Caldas, MG. 10 a 14 de agosto de 1998. Vol. 1, p. 559-572.

NORTH, D. C. Institutions, institutional, change and economic performance. Cambridge University Press, 1990. 152 p.

OCB - Organização das Cooperativas Brasileiras (2003). Cooperativismo no Brasil - Estatísticas dezembro/2003. Disponível em $<$ http://www.ocb.org.br>. Acesso em 13/07/2004.

ROCHA JÚNIOR. W.F. Análise do agronegócio da erva-mate com o enfoque da nova economia institucional e o uso da matriz estrutural prospectiva. 2001. 110 f. Tese (doutorado em Engenharia da Produção) - Universidade Federal de Santa Catarina, Florianópolis.

SAES, M. S. M. Organizações e instituições. In: ZYLBERSZTAJ, D. NEVES. M. F. (Orgs). Economia \& gestão dos negócios agroalimentares. São Paulo, Pioneira/PENSA, 2000. p. 165-186. 
SHIKIDA, P. F. A.; FRANTZ, R. L. Estratégias de atuação da ALCOPAR (PR) em face da desregulamentação setorial e da globalização da economia. In: MONTOYA, M. A.; ROSSETO, C. R. (Orgs.); Abertura econômica e competitividade no agronegócio brasileiro: impactos regionais e gestão estratégica. Passo Fundo : Editora UPF, 2002. p.181-205.

SHIKIDA, P. F.A. A evolução diferenciada da agroindústria canavieira no Brasil de 1975 a 1995. 1997. 191 f. Tese (Doutorado em Ciências Aplicadas) - Escola Superior de Agricultura "Luiz de Queiroz”, Universidade de São Paulo, Piracicaba.

SHIKIDA, P. F.A. A evolução diferenciada da agroindústria canavieira no Brasil de 1975 a 1995. Cascavel: Edunioeste, 1998. 149 p.

UNICAMP. JORNAL DA UNICAMP. Ano XV -N 161 - Abril 2001. Disponível em <http://www.unicamp.br/unicamp/unicamp_hoje/ju/ abril2001/pag06abril2001.htm> acesso em 11/08/04.

WILLIAMSON, O. The economic institutions of capitalism: firms, markets, relational contracting. The free press, New York.1991, 450 p.

WILLIAMSON, O. E. The Economic institutions of capitalism. USA: Macmillan. 1985. 450p.

\footnotetext{
Abstract - This study about the directive thought from sugarcane Agro Industry Cooperatives from Paraná State objectives to rescue the concepts of the New Institutional Economy and to investigate the level of treatment of the cooperatives management about the transaction costs, administration forms of the contracts as well as the government forms that manage the Sugarcane Agro Industrial Cooperative segment. What is looked for in this work is to explore the common aspects, tangent points that can bring useful elements for the application of the organization science and the institutions to the study of the Sugarcane Agro Industry Cooperatives.
}

Keywords: Cooperatives, sugarcane agro industry, New Institutional Economy, cooperatives management, Paraná. 